\title{
Early acute respiratory distress syndrome after pneumonectomy: Presentation, management, and short- and long-term outcomes
}

Kim Blanc, MD, ${ }^{a}$ Rym Zaimi, MD, ${ }^{b}$ Agnès Dechartres, MD, PhD,${ }^{c}$ Aurélie Lefebvre, MD, ${ }^{a}$ Aurélie Janet-Vendroux, MD, ${ }^{\mathrm{b}}$ Emelyne Hamelin-Canny, MD, ${ }^{\mathrm{b}}$ Nicolas Roche, MD, PhD, ${ }^{\mathrm{a}}$ Marco Alifano, $\mathrm{MD}, \mathrm{PhD},{ }^{\mathrm{b}}$ and Antoine Rabbat, $\mathrm{MD}^{\mathrm{a}}$

\section{ABSTRACT}

Objective: Postpneumonectomy acute respiratory failure leading to invasive mechanical ventilation carries a severe prognosis, especially when acute respiratory distress syndrome develops. The aim of this study was to describe the risk factors, management, and outcome of postpneumonectomy acute respiratory distress syndrome.

Methods: We retrospectively reviewed the clinical files of patients undergoing pneumonectomy in a single center between 2005 and 2015. Risk factors for acute respiratory distress syndrome, management characteristics, and short- and longterm outcomes were assessed.

Results: Among the 543 patients undergoing pneumonectomy, 89 (16.4\%) needed reintubation within the 30th postoperative day, including 60 (11\%) who developed acute respiratory distress syndrome. At multivariate analysis, rightside pneumonectomy (odds ratio [OR], 2.75; 95\% confidence interval [CI], 1.51-5.02; $P=.0009)$ and higher Charlson Comorbidity Index (OR, 1.26; 95\% CI, 1.07-1.49; $P=.007$ ) were identified as independent risk factors for acute respiratory distress syndrome. Operative mortality was $8.1 \%$ for all pneumonectomies, 43.8\% $(n=39 / 89)$ in intubated patients, and 56.7\% $(34 / 60)$ in patients with acute respiratory distress syndrome. Mortality was higher in severe $(25 / 36$, $69.4 \%)$ than in mild or moderate acute respiratory distress syndrome $(9 / 24$, $37.5 \%, P=.014)$. Logistic regression identified 3 independent predictors of operative mortality in patients with acute respiratory distress syndrome: age (OR, 1.08; 95\% CI, 1.01-1.15; $P=.02$ ), right pneumonectomy (OR, 5.97; 95\% CI, $1.33-26.71 ; P=.02)$, and severe acute respiratory distress syndrome (OR, 7.19; $95 \%$ CI, 1.74-29.73; $P=.006$ ). Five-year survival was $17.6 \%$ for patients with acute respiratory distress syndrome.

Conclusions: Acute respiratory distress syndrome is a severe early complication of pneumonectomy with a poor outcome. The low survival underlines the need for novel management strategies. (J Thorac Cardiovasc Surg 2018;156:1706-14)

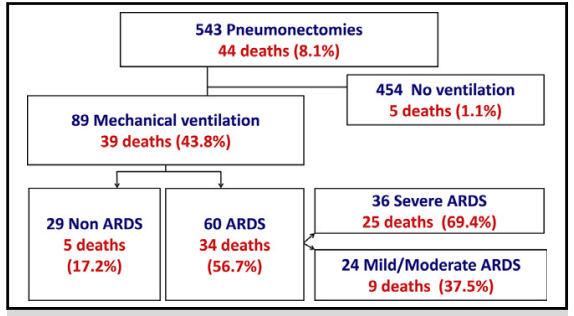

Postpneumonectomy operative deaths. ARDS, Acute respiratory distress syndrome.

\section{Central Message}

Right-side pneumonectomy and comorbidities are risk factors of postpneumonectomy ARDS, the outcome of which is poor. Operative mortality is associated with age, right pneumonectomy, and ARDS severity.

\section{Perspective}

ARF, leading to IMV and ARDS, is not an infrequent complication of pneumonectomy. Severity of ARDS, age, and right-side pneumonectomy are independent risk factors of operative mortality. The low survival of postpneumonectomy ARDS underlines the need for developing new management strategies.

See Editorial Commentary page 1715.

See Editorial page 1704.
Lung resection can be associated with a high postoperative morbidity. ${ }^{1,2}$ Postoperative acute respiratory failure (ARF) requiring invasive mechanical ventilation (IMV) carries a

From the Departments of ${ }^{\mathrm{a} C h e s t ~ D i s e a s e ~ a n d ~ R e s p i r a t o r y ~ I n t e n s i v e ~ C a r e, ~}{ }^{\mathrm{b}}$ Thoracic Surgery, and ${ }^{\mathrm{c}}$ Center for Clinical Epidemiology, Hôtel Dieu, Cochin Hospital, HUPC, APHP, Paris Descartes University, Paris, France.

Received for publication Sept 29, 2017; revisions received May 22, 2018; accepted for publication June 2, 2018; available ahead of print July 27, 2018.

Address for reprints: Marco Alifano, MD, PhD, Service de Chirurgie Thoracique, Hôpitaux Universitaires Paris Centre, Hôpital Cochin, 27 rue du Faubourg Saint Jacques, 75679 Paris cedex 14, France (E-mail: marco.alifano@cch.aphp.fr). $0022-5223 / \$ 36.00$

Copyright (c) 2018 by The American Association for Thoracic Surgery https://doi.org/10.1016/j.jtcvs.2018.06.021 high mortality rate, especially in patients developing acute respiratory distress syndrome (ARDS) (20\%-50\% mortality rate). ${ }^{3-5}$ Previous studies reported a frequency of ARDS after lung resection of $1 \%$ to $8 \%$ with a high mortality rate from ARDS, ranging from $30 \%$ to $80 \% .^{3,4,6,7}$

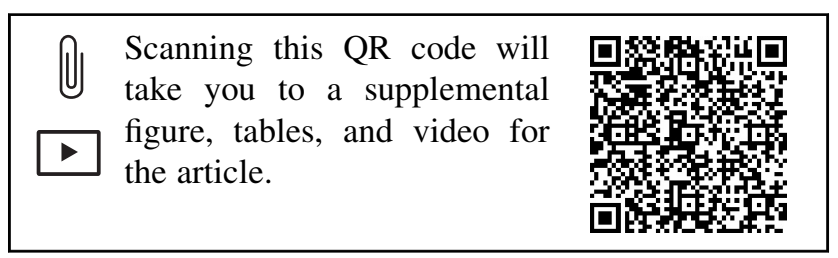




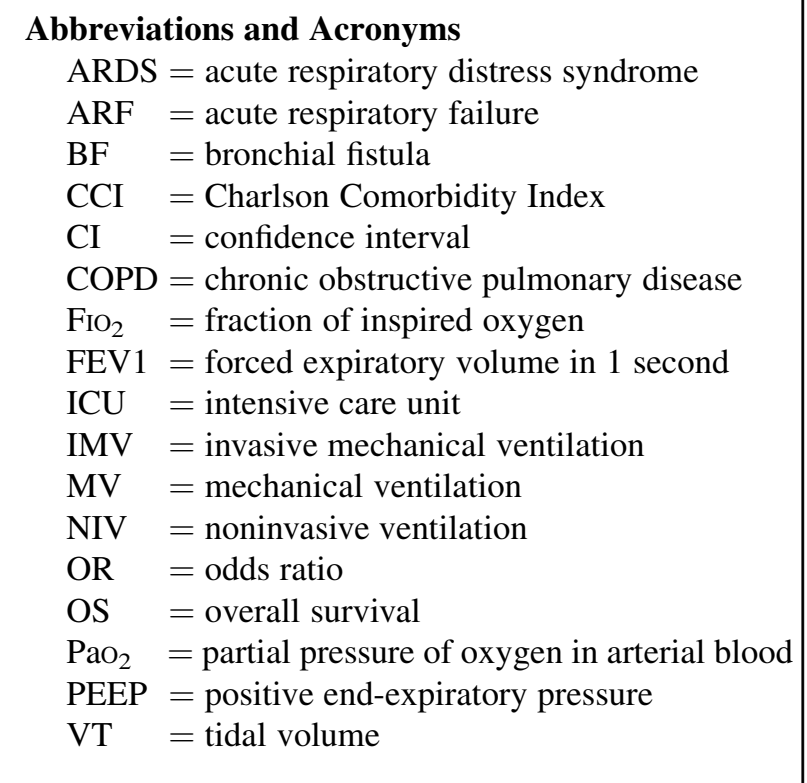

Among pulmonary resections, pneumonectomy is associated with the highest postoperative mortality rates, with figures ranging from $6 \%$ to $9 \% .{ }^{8}$ In a recent large cohort study including 543 patients with pneumonectomies for lung cancer, we observed a $7.7 \%$ 30-day mortality rate. ARF requiring reintubation was a frequent and severe complication of pneumonectomy, occurring in $16.4 \%$ of cases and associated with a high $(43.8 \%)$ in-hospital mortality. In that study, early ARDS occurred within 30 days after pneumonectomy in 60 of 543 patients. When comparing survivors and nonsurvivors, logistic regression analysis identified 3 independent predictors of 30-day mortality: occurrence of ARDS (odds ratio [OR], 7.33; 95\% confidence interval $[\mathrm{CI}], 1.47-36.67 ; P=.015)$, Simplified Acute Physiologic Score 2 at intensive care unit (ICU) admission greater than 25 (OR, 4.57; 95\% CI, 1.19$17.52 ; P=.027$ ), and right-side pneumonectomy (OR, $4.95 ; 95 \%$ CI, $1.19-20.54 ; P=.028$ ) (Blanc and colleagues, unpublished data).

The considerable weight of ARDS as a determinant of prognosis in that study underlines the need to better decipher its risk factors and outcomes. Few studies have addressed risk factors for postpneumonectomy ARDS. ${ }^{6,7,9-12}$ Patient-related preoperative factors remain a matter of debate, and some studies with large populations failed to find significant associations. ${ }^{7}$ The roles of intraoperative protective ventilation (including low tidal volume [VT] and low plateau pressure associated with positive endexpiratory pressure [PEEP]) and restricted fluid administration suggested in animal models have been confirmed by clinical studies ${ }^{12-14}$ and may have affected the outcome in recent years. Furthermore, only a limited number of studies have focused on the outcome of patients with postpneumonectomy ARDS. ${ }^{3-5,7}$ Most of these studies were performed several years ago and included a limited number of patients, and important prognostic data were missing.

During the last years, the rate of pneumonectomy has decreased because of parenchymal-sparing resections (bronchial and bronchovascular sleeves), better selection of patients, and increase in nonsurgical management of locally advanced lung cancers. Postoperative care has also changed, and fast-track procedures (early recovery after surgery) are now the rule. In addition, the definition and severity criteria of ARDS have been better established, and management of ARF and ARDS has markedly changed. ${ }^{15,16}$ Together with the paucity of available data in this area, all these changes make it necessary to expand our knowledge of the risk factors and outcomes of postpneumonectomy ARDS.

The present study deals with the same cohort of pneumonectomy cases experiencing ARF requiring mechanical ventilation (MV) studied by Blanc and colleagues, but, in the present study, we studied in detail the risk factors, management modalities, and outcome of postpneumonectomy ARDS and compared clinical characteristics and management, as well as short- and long-term outcomes of reintubated patients with and without ARDS. We also studied the baseline clinical characteristics, intraoperative management, and characteristics of patients at postoperative ICU admission to study the predictive factors of death related to postpneumonectomy ARDS.

\section{MATERIALS AND METHODS \\ Study Design and Patients}

This was a single-center retrospective cohort study. Files from all consecutive adult patients who underwent pneumonectomy in our institution between January 2005 and December 2015 were retrospectively retrieved. The research was conducted according to recommendations outlined in the Helsinki Declaration and to French laws on Biomedical Research. Institutional Review Board approval was obtained (CERC-SFCTCV-2015-11-413-16-16-16AlMa/CPP HUPC). All patients or relatives (in case of deceased patients) gave their informed consent to participate and allowed the use of their data. Indications to surgery were established according to French Thoracic and Cardiovascular Society guidelines (detailed in Supplemental Material). All patients were hospitalized in our ICU after surgery.

\section{Data Collection}

Clinical and pathologic parameters were collected, as well as intraoperative parameters and postoperative ICU data (including ventilation support parameters) detailed in the Supplemental Material.

We identified patients requiring early reintubation and IMV for postpneumonectomy ARF (within 30 days). Indications for reintubation were recorded, as well as nonrespiratory postoperative complications, and the diagnosis of all postoperative complications was made according to predefined definitions (Supplemental Material). Simplified Acute Physiologic Score 2 at ICU admission was also recorded.

Within the group of early (within 30 days after pneumonectomy) reintubated patients, we identified patients who developed ARDS. In agreement with Berlin definitions, ${ }^{15}$ ARDS was defined by the absence of 
hydrostatic or cardiogenic pulmonary edema, and partial pressure of arterial oxygen and fraction of inspired oxygen $\left(\mathrm{PaO}_{2} / \mathrm{FIO}_{2}\right) 300 \mathrm{~mm} \mathrm{Hg}$ or less; 3 categories of severity were identified: ${ }^{15}$ mild $\left(200 \mathrm{~mm} \mathrm{Hg}<\mathrm{PaO}_{2} / \mathrm{FiO}_{2}\right.$ $\leq 300 \mathrm{~mm} \mathrm{Hg})$, moderate $\left(100<\mathrm{PaO}_{2} / \mathrm{FIO}_{2} \leq 200 \mathrm{~mm} \mathrm{Hg}\right)$, and severe ARDS $\left(\mathrm{PaO}_{2} / \mathrm{FIO}_{2} \leq 100 \mathrm{~mm} \mathrm{Hg}\right)$; all were assessed at a PEEP level $5 \mathrm{~cm}$ $\mathrm{H}_{2} \mathrm{O}$ or greater. Concerning ARF support, the following data were recorded: use of noninvasive ventilation (NIV) before orotracheal reintubation and IMV, delay between ICU admission and reintubation, and severity of ARF at reintubation. The decision to implement NIV for ARF before intubation was left to the clinicians. IMV modalities were recorded 24 hours after intubation, under sedation, and after hemodynamic optimization, including controlled fluid loading and vasopressors if needed. The following MV parameters were measured: VT, respiratory rates, plateau pressure, and PEEP level (Supplemental Material). ARDS "rescue" treatments, including prone or lateral positioning, neuromuscular blockade agents, inhaled nitric oxide, corticosteroids administration, and extracorporeal membrane oxygenation use, were also recorded.

In all reintubated patients, we calculated the Sequential Organ Failure Assessment score at the time of intubation and recorded the need for renal replacement therapy and need of vasopressors. Duration of IMV and IMVrelated complications were also recorded, including occurrence of bronchial fistula (BF) and empyema.

Operative mortality was defined as all deaths occurring before postoperative day 30 or during the same hospitalization as surgery, even after postoperative day 30. ICU and hospital length of stay were obtained for all patients. For discharged patients, survival status was assessed by direct phone interview or from registries of the municipality of birth. Survival was calculated from the date of surgery and last alive contact or death. Patients who could not be contacted by telephone and were not found as dead in the death registries were censored on November 15, 2015.

\section{Statistical Analysis}

Descriptive analysis involved use of frequencies and percentages for categoric variables and median (Q1Q3) as appropriate for quantitative variables. We aimed to evaluate which preoperative and intraoperative characteristics were independently associated with ARDS. To do so, we first conducted univariate analyses by comparing preoperative and intraoperative variables between patients presenting ARDS and those who did not, with chi-square tests or Fisher exact tests as appropriate for categoric variables, and Student $t$ test or Wilcoxon rank-sum tests for quantitative variables. Selection of variables for multivariate logistic regression models was based on univariate analyses (inclusion of all variables associated with the event of interest with a $P<.05$ ) and on clinical judgment or literature review. Quantitative variables were not transformed for use in the models. We evaluated collinearity by checking that the variance inflation factors were all less than 2 (indicating little to moderate correlation between variables). In the main multivariate analysis, we included all preselected variables. We also performed a sensitivity analysis using a stepwise variable selection with the likelihood ratio test $P$ value stopping rule of .1 to enter and .05 to remain in the final model. We used the c-statistic as a measure of model performance. We used the same process among all patients with ARDS to identify factors associated with 30 -day mortality. $P$ values were 2 tailed. Finally, we described long-term survival using the Kaplan-Meier method; comparisons were performed by log-rank. Statistical analysis were performed using SAS version 9.3 (SAS Institute Inc, Cary, NC) and R version 3.2.3 (R Core Team 2015, https://www.R-project.org/).

\section{RESULTS}

A total of 543 patients underwent pneumonectomy in the time frame of the study. Baseline characteristics of the whole population and in patients with and without ARDS are detailed in Table 1. There was no intraoperative death. Eighty-nine patients $(16.4 \%)$ required reintubation and
IMV within the 30 postoperative days. Sixty of these patients (67.4\% of IMV cases and $11.05 \%$ [95\% CI, 8.41-13.69] of all pneumonectomy cases) developed ARDS. Mild, moderate, and severe ARDS occurred in 3 patients (5\%), 21 patients $(35 \%)$, and 36 patients $(60 \%)$, respectively.

Among intubated patients $(\mathrm{n}=89)$, no significant difference was found between patients with and without ARDS in terms of airway management, intraoperative IMV settings, intraoperative plateau pressure level, amount of fluid administration or amount of red blood cell transfusion, and duration of operation (Table E1). In patients with ARDS $(n=60)$, day 3 Sequential Organ Failure Assessment score was significantly higher than in those without ARDS $(\mathrm{n}=29)(P=.002)$. More patients in the ARDS group had postoperative pneumonia $(76.7 \%$ vs $38 \%$, $P=.0004)$, severe sepsis $(86.7 \%$ vs $38 \%, P<.0001)$, postoperative hemorrhagic shock ( $31 \%$ vs $11.7 \%, P=.003$ ), and $\mathrm{BF}(\mathrm{n}=15,25 \%$ vs $0 \%, P=.001)$ than in the nonARDS group (Tables E2 and E3).

\section{Risk Factors for Acute Respiratory Distress Syndrome}

Comparison of baseline characteristics between patients presenting $(\mathrm{n}=60,11 \%)$ or not presenting $(\mathrm{n}=483$, $89 \%$ ) with postpneumonectomy ARDS is shown in Table 1. Patients presenting with postpneumonectomy ARDS more frequently had right-side pneumonectomy $(\mathrm{n}=41[68 \%]$ vs $\mathrm{n}=203[42 \%], P=.0001)$, diabetes $(\mathrm{n}=11[18.3 \%]$ vs $\mathrm{n}=41[8.5 \%], P=.01)$, chronic cardiac disease $(\mathrm{n}=18[30 \%]$ vs $\mathrm{n}=78[16.1 \%], P=.008)$, chronic obstructive pulmonary disease (COPD) $(\mathrm{n}=36$ $[60 \%]$ vs $\mathrm{n}=220[45.6 \%], P=.03)$, and higher Charlson Comorbidity Index (CCI) (6 [5-7] vs 5 [4-6], $P<.0001)$. They also had lower predictive postoperative forced expiratory volume in 1 second (FEV1) (45 [38-52], vs 49 [43-57], $P=.007)$. ARDS occurred more frequently in patients undergoing carinal resection $(\mathrm{n}=8[13.3 \%]$ vs $\mathrm{n}=24$ $[4.9 \%], P=.02)$.

At multivariate analysis (Table 2), only right side (OR, 2.75; 95\% CI $1.51-5.02, P=.0009)$ and higher CCI (OR, 1.26; 95\% CI, 1.07-1.49, $P=.007$ ) were identified as independent risk factors for postpneumonectomy ARDS.

\section{Early Management and Outcome}

Operative mortality was $8.1 \%(n=44 / 543)$ in the whole population of patients undergoing pneumonectomy, $43.8 \%$ $(\mathrm{n}=39 / 89)$ in reintubated patients, and $56.7 \%(\mathrm{n}=34 / 60)$ in patients with ARDS. Mortality was significantly higher in severe ARDS $(\mathrm{n}=25 / 36,69.4 \%)$ than in mild or moderate $\operatorname{ARDS}(\mathrm{n}=9 / 24,37.5 \% ; P=.014)$.

The main characteristics of ARDS postoperative survivors and nonsurvivors and outcomes are displayed in Tables 3 and 4. Nonsurvivors were older (67.5 [63-75] years vs 59 [55-67] years, $P=.003$ ), more frequently had right 
TABLE 1. Patient characteristics: Whole population of subjects receiving pneumonectomy

\begin{tabular}{|c|c|c|c|c|}
\hline & $\begin{array}{l}\text { All pneumonectomies } \\
\qquad \mathrm{n}=\mathbf{5 4 3} \\
\end{array}$ & $\begin{array}{c}\text { ARDS } \\
n=60(11 \%)\end{array}$ & $\begin{array}{c}\text { Non-ARDS } \\
\mathrm{n}=\mathbf{4 8 3}(\mathbf{8 8 . 9} \%) \\
\end{array}$ & $P$ value \\
\hline Male gender, n (\%) & $398(73)$ & $48(80)$ & $350(72.5)$ & .21 \\
\hline Age (y), median [Q1Q3] & 63 [56-69] & $65[57-71]$ & $63[56-69]$ & .10 \\
\hline Smokers, n (\%) & $468(86.2)$ & $53(88.3)$ & $415(85.9)$ & .61 \\
\hline Active smokers, $\mathrm{n}(\%)$ & $116(21.4)$ & $18(30)$ & $98(20.3)$ & .08 \\
\hline Obesity, n (\%) & $52(9.6)$ & $8(13.3)$ & $44(9.1)$ & .30 \\
\hline Chronic alcoholic abuse, n (\%) & $89(16.4)$ & $14(23.3)$ & $75(15.5)$ & .12 \\
\hline Diabetes mellitus, n (\%) & $52(9.6)$ & $11(18.3)$ & $41(8.5)$ & .01 \\
\hline Systemic arterial hypertension, $\mathrm{n}(\%)$ & $167(31)$ & $24(40)$ & $143(29.6)$ & .1 \\
\hline Chronic cardiac disease, $\mathrm{n}(\%)$ & $96(17.7)$ & $18(30)$ & $78(16.1)$ & .008 \\
\hline COPD, n (\%) & $256(46.9)$ & $36(60)$ & $220(45.6)$ & .03 \\
\hline CCI, median [Q1Q3] & $5[4-6]$ & $6[5-7]$ & $5[4-6]$ & $<.0001$ \\
\hline $\mathrm{PS}>1, \mathrm{n}(\%)$ & $103(18.9)$ & $11(18.3)$ & $92(19.1)$ & .89 \\
\hline Preoperative FEV1 ( $\%$ predicted), median [Q1Q3] & $77[69-92]$ & $76[69-85]$ & 78 [68-93] & .19 \\
\hline FEV1/FVC, median [Q1Q3] & $72[64-79]$ & $72[65-78]$ & $72[64-79]$ & .67 \\
\hline Predictive postoperative FEV1 (\% predicted), median [Q1Q3] & $46[39-52]$ & $45[38-52]$ & 49 [43-57] & .007 \\
\hline History of lung cancer, $\mathrm{n}(\%)$ & $35(6)$ & $6(10)$ & $29(6)$ & .26 \\
\hline History of nonlung cancer, n ( $\%)$ & $70(13)$ & $9(15)$ & $61(12.6)$ & .60 \\
\hline Right side pneumonectomy, n (\%) & $244(44.9)$ & $41(68)$ & $203(42)$ & .0001 \\
\hline $\begin{array}{l}\text { Pathology, } \mathrm{n}=512 \\
\text { SCC, } \mathrm{n}(\%) \\
\text { Adenocarcinoma } \\
\text { Other histologic types } \\
\text { Mesothelioma } \\
\text { Metastasis } \\
\text { Benign disease }\end{array}$ & $\begin{array}{c}243(44.8) \\
153(28.2) \\
116(21.4) \\
24(4.4) \\
4(0.7) \\
3(0.5)\end{array}$ & $\begin{array}{l}28(46.7) \\
14(23.3) \\
11(18.3) \\
3(5) \\
2(3.3) \\
2(3.3)\end{array}$ & $\begin{array}{c}215(44.5) \\
139(28.7) \\
105(21.7) \\
21(4.3) \\
2(0.4) \\
1(0.2)\end{array}$ & .03 \\
\hline Neoadjuvant chemotherapy, n (\%) & $181(33.3)$ & $16(26.7)$ & $165(34.2)$ & .24 \\
\hline Neoadjuvant radiotherapy, n (\%) & $12(2.0)$ & $1(1.7)$ & $11(2.3)$ & 1 \\
\hline Extended pneumonectomy, n (\%) & $313(58)$ & $33(55)$ & $280(57.9)$ & .66 \\
\hline Extrapleural pneumonectomy, n (\%) & $37(6.8)$ & $6(10)$ & $31(6.4)$ & .28 \\
\hline Completion pneumonectomy, n (\%) & $36(6.6)$ & $7(11.7)$ & $29(6)$ & .1 \\
\hline Carinal resection, n $(\%)$ & $32(6)$ & $8(13.3)$ & $24(4.9)$ & .02 \\
\hline NSCLC $\mathrm{p}$ stage, $\mathrm{n}(\%) \mathrm{n}=502$ & & 52 & 438 & .42 \\
\hline IA & $23(5)$ & $4(6.7)$ & $18(3.7)$ & \\
\hline IB & $25(5)$ & $5(8.3)$ & $19(3.9)$ & \\
\hline IIA & $56(11)$ & $2(3.3)$ & $52(10.8)$ & \\
\hline IIB & 67 (13) & $10(16.7)$ & $52(10.8)$ & \\
\hline IIIA & $271(54)$ & $23(38.3)$ & $248(51.3)$ & \\
\hline IIIB & $36(7)$ & $6(10)$ & $30(6.2)$ & \\
\hline IV & $21(4)$ & $2(3.3)$ & $19(3.9)$ & \\
\hline
\end{tabular}

Continuous variables are reported as median [interquartile range $\{\mathrm{IQR}\}(\mathrm{Q} 1 \mathrm{Q} 3)]$. Categoric variables are reported as number (percentages). ARDS, Acute respiratory distress syndrome; $C O P D$, chronic obstructive pulmonary disease; $C C I$, Charlson Comorbidity Index; $P S$, performance status; $F E V$, forced expiratory volume; $F V C$, forced vital capacity; $S C C$, squamous cell carcinoma; NSCLC, non-small cell lung cancer; $p$ stage, postchirurgical stage.

pneumonectomy $(\mathrm{n}=28[82.3 \%]$ vs $\mathrm{n}=15[50.0 \%]$, $P=.008)$, and more frequently had postoperative acute kidney injury $(\mathrm{n}=18[52.9 \%]$ vs $\mathrm{n}=6[23.08 \%], P=.02)$ than survivors. Logistic regression identified 3 independent predictors of operative mortality: age (OR, 1.08 per additional year; $95 \% \mathrm{CI}, 1.01-1.15, P=.02)$, right 
TABLE 2. Multivariate analysis of risk factors of occurrence of postoperative acute respiratory distress syndrome $(n=531)$

\begin{tabular}{lcc}
\hline \multicolumn{1}{c}{ Characteristics } & OR $(\mathbf{9 5} \% \mathbf{C I})$ & $\boldsymbol{P}$ value \\
\hline Side (right vs left) & $2.75(1.51-5.02)$ & .0009 \\
Carinal resection & $1.98(0.80-4.88)$ & .14 \\
CCI & $1.26(1.07-1.49)$ & .007 \\
Diabetes & $1.66(0.75-3.67)$ & .21 \\
Chronic cardiac disease & $1.50(0.76-2.95)$ & .24 \\
COPD & $1.37(0.76-2.50)$ & .30 \\
\hline
\end{tabular}

$O R$, Odds ratio; $C I$, confidence interval; $C C I$, Charlson Comorbidity Index; $C O P D$, chronic obstructive pulmonary disease.

pneumonectomy (OR, 5.97; 95\% CI, 1.33-26.71, $P=.02$ ), and severe ARDS (OR, 7.19; 95\% CI, 1.74-29.73, $P=.006)$.

\section{Long-Term Outcome}

Median and 5-year overall survival (OS) of the whole population of intubated patients $(n=89$, including intubated patients with and without ARDS), were 7 months and $27.2 \%$, respectively (95\% CI, 17.4-39.8). Median survivals in intubated patients with and without ARDS were 1.3 month and 57.8 months, respectively; 5-year OS figures were $17.6 \%$ (95\% CI, 9.4-32.7) and $43.4 \%$, respectively (95\% CI, 20.5-69.6; $P=.001$ log-rank) (Figure 1). There was no difference in survival between the different ARDS categories (Figure 2).

Among postoperative survivors $(\mathrm{n}=50)$, median and 5 -year OS were 38 months and $39.2 \%$, respectively $(95 \%$ CI, 21.1-60.9), in patients with ARDS, and not reached and $52.5 \%$, respectively $(95 \% \mathrm{CI}, 24.3-79.2 ; P=.18$ log-rank), in those without ARDS.

Among 90-day survivors $(\mathrm{n}=49)$, median and 5-year OS were 38 months and $40.7 \%$, respectively $(95 \%$ CI, 34.8 72.6), in patients with ARDS, and not reached and
$54.8 \%$, respectively $(95 \% \mathrm{CI}, 25.2-81.4 ; P=.15 \mathrm{log}$ rank), in those without ARDS.

\section{DISCUSSION}

In the present study, we provide evidence that ARDS is frequent among patients with early ARF requiring reintubation after pneumonectomy. Severe ARDS as defined in the Berlin consensus statement represented more than half of ARDS cases. Our prevalence of ARF and ARDS is comparable to that reported in smaller series. ${ }^{3,4}$

We identified only right side of pneumonectomy and higher CCI as independent risk factors of ARDS after pneumonectomy. Several studies reported a higher postoperative rate of early ARDS after right-side pneumonectomy. ${ }^{8,17,18}$ This could relate to several factors, including the usual predominance of the right lung in terms of perfusion and ventilation and the higher postoperative pulmonary arterial pressure after right than left pneumonectomy. ${ }^{19}$ All of our patients had a preoperative lung perfusion scan and a transthoracic echocardiography in their preoperative evaluation. These recommended noninvasive tests may not be sensitive enough to detect mild preoperative pulmonary hypertension and to predict severe postpneumonectomy pulmonary hypertension, which has been reported to be associated with postpneumonectomy ARDS..$^{20-22}$ Apart from preoperative ventilatory function, the adequacy of pulmonary vascular bed and circulation after extended lung resection may be crucial to predict postoperative ARF and ARDS. Preoperative assessment of pulmonary vascular resistance by right heart catheterization at rest and during exercise has been suggested by Fee and colleagues. ${ }^{23}$ These authors observed that high pulmonary vascular resistance was a better predictor of mortality than simple pulmonary function tests, which suggests a possible role of secondary pulmonary hypertension caused by a reduction in the pulmonary capillary bed as a

TABLE 3. Baseline characteristics of survivors versus nonsurvivors among the 60 patients with acute respiratory distress syndrome

\begin{tabular}{|c|c|c|c|c|}
\hline & $\begin{array}{c}\text { Patients with ARDS } \\
\mathrm{n}=60(67.4 \%)\end{array}$ & $\begin{array}{c}\text { Alive } \\
\mathrm{n}=\mathbf{2 6}(\mathbf{4 3 . 3} \%)\end{array}$ & $\begin{array}{c}\text { Operative mortality } \\
\mathbf{n}=\mathbf{3 4}(56.7 \%)\end{array}$ & $P$ value \\
\hline Age $(\mathrm{y})$, median [IQR] & $65[57.5-71]$ & 59 [55-67] & $67.5[63-75]$ & .003 \\
\hline Male gender & $48(80)$ & $21(80.8)$ & $27(79.4)$ & .90 \\
\hline Smokers, n (\%) & $53(88.3)$ & $24(92.3)$ & $29(85.2)$ & $.69^{*}$ \\
\hline Active smokers, n (\%) & $18(30)$ & $10(38.5)$ & $8(23.5)$ & .21 \\
\hline FEV1, median (IQR) & $76[69-85]$ & 75 [70-83] & 76.5 [69-85] & .68 \\
\hline Obesity, n (\%) & $8(13.3)$ & $2(7.7)$ & $6(17.6)$ & $.45^{*}$ \\
\hline Chronic cardiac disease, $\mathrm{n}(\%)$ & $18(30)$ & $7(26.9)$ & $11(32.3)$ & .65 \\
\hline CCI score, median [IQR] & $6[5-7]$ & $5.5[5.0-7.0]$ & $6[5-7]$ & .22 \\
\hline Right side, $\mathrm{n}(\%)$ & $41(68.3)$ & $15(50.0)$ & $28(82.3)$ & .008 \\
\hline Carina resection & $8(13.3)$ & $4(15.4)$ & $4(11.8)$ & $.71 *$ \\
\hline
\end{tabular}

Continuous variables are reported as median [IQR (Q1Q3)]. Categoric variables are reported as number (percentages). ARDS, Acute respiratory distress syndrome; IQR, interquartile range; $F E V$, forced expiratory volume; $C C I$, Charlson Comorbidity Index. *Fisher exact test. 
TABLE 4. Characteristics at intensive care unit admission, postoperative complications, and outcomes of survivors versus nonsurvivors among the 60 patients with acute respiratory distress syndrome

\begin{tabular}{|c|c|c|c|c|}
\hline & $\begin{array}{c}\text { Patients with } \\
\text { ARDS n }=60(67.4 \%)\end{array}$ & $\begin{array}{c}\text { Alive } \\
\mathbf{n}=\mathbf{2 6}(\mathbf{4 3 . 3} \%) \\
\end{array}$ & $\begin{array}{c}\begin{array}{c}\text { Operative } \\
\text { mortality } \\
\mathbf{n}=\mathbf{3 4}(56.7 \%)\end{array} \\
\end{array}$ & $P$ value \\
\hline SAPS2 score at admission, median [IQR] & $26[16-35.5]$ & $21[16-34]$ & 28 [21-36] & .12 \\
\hline Pneumonia, n (\%) & $46(76.7)$ & $22(84.6)$ & $24(70.6)$ & .20 \\
\hline Hemorrhagic shock, $\mathrm{n}(\%)$ & $7(11.7)$ & $1(3.8)$ & $6(17.6)$ & $.13^{*}$ \\
\hline Sepsis, $\mathrm{n}(\%)$ & $52(86.7)$ & $23(88.5)$ & $29(85.3)$ & $1 *$ \\
\hline Acute kidney injury, $\mathrm{n}(\%)$ & $24(40)$ & $6(23.08)$ & $18(52.9)$ & .02 \\
\hline NIV for ARF before reintubation, $\mathrm{n}(\%)$ & $44(73.3)$ & $22(84.6)$ & $22(64.7)$ & .08 \\
\hline Time between surgery and reintubation (d), median [IQR] & $3[1-4]$ & $2[1-3]$ & $3[1-4.5]$ & .20 \\
\hline $\mathrm{PaO}_{2} / \mathrm{FIO}_{2}$ at reintubation, median [IQR] & $142[109-200]$ & $149[120-190]$ & $126[98.5-294]$ & .46 \\
\hline SOFA at intubation, median [IQR] & 9 [6-12] & $8.5[7-10.5]$ & $11[5-12]$ & .34 \\
\hline Mild moderate ARDS & $24(40)$ & $15(57.7)$ & $9(26.5)$ & \\
\hline Severe ARDS, n (\%) & $36(60)$ & $11(42.3)$ & $25(73.5)$ & .014 \\
\hline Prone or lateral positioning, $\mathrm{n}(\%)$ & $18(30)$ & 4 & 14 & $.05^{*}$ \\
\hline Neuromuscular blockade, n (\%) & $38(63.3)$ & 18 & 20 & $.43 *$ \\
\hline High-dose corticosteroids, n ( $\%)$ & $11(18.3)$ & $3(11.5)$ & $8(23.5)$ & .32 \\
\hline Inhaled NO, n (\%) & $19(31.7)$ & $5(19.2)$ & $14(41.2)$ & $.008^{*}$ \\
\hline ECMO, n (\%) & $2(3.3)$ & $0(0)$ & $2(6.3)$ & $.49^{*}$ \\
\hline Vasopressors, n (\%) & $48(80)$ & $21(75)$ & $27(84.4)$ & .36 \\
\hline RRT, n (\%) & $9(15)$ & $1(3.8)$ & $8(23.5)$ & $.06^{*}$ \\
\hline $\mathrm{BF}, \mathrm{n}(\%)$ & $15(25)$ & $5(19.2)$ & $10(29.4)$ & .37 \\
\hline Empyema, n (\%) & $14(23)$ & $6(23.1)$ & $8(23.5)$ & .97 \\
\hline Duration of MV (d, median [IQR] & $11[5-26]$ & 20 [7-39] & $10[3-15.5]$ & .007 \\
\hline ICU LOS, median [IQR] & 18 [10-36.5] & $28.5[17-50]$ & $13.5[6-23]$ & .0006 \\
\hline Hospital LOS, median [IQR] & $21.5[12-40.5]$ & $35.5[22-59]$ & 14 [7-23] & $<.001$ \\
\hline
\end{tabular}

determinant of ARF and ARDS after right pneumonectomy. Furthermore, an older study showed that high pulmonary artery pressure measured intraoperatively in patients undergoing pneumonectomy was associated with an increased incidence of cardiorespiratory complications and mortality. ${ }^{24}$ Unfortunately, we are unable to provide any data concerning pulmonary vascular resistance in our patients. Right heart catheterization was only performed preoperatively in a few of them in whom pulmonary hypertension was suspected after initial noninvasive evaluation including cardiac echography. In addition, in most settings, right heart catheterization cannot be performed systematically.

In our study, no lung function variable was associated with the occurrence of postpneumonectomy ARDS in multivariate analysis. Some investigators identified FEV1 as a possible risk factor, but others failed to confirm this association. ${ }^{2,6,7}$ Although the importance of predictive postoperative FEV1 in predicting pulmonary complications and mortality after lung resection has been suggested in some studies, this association remains a matter of controversy: In a study analyzing 146 patients undergoing pneumonectomy, univariate analysis showed a significant association of predictive postoperative FEV1 with postoperative ARDS, but multivariate analysis showed that the independent factors associated with occurrence of ARDS were only prior radiotherapy, perfusion of the remaining lung of $55 \%$ or less, and high intraoperative fluid load, but not predictive postoperative FEV1. ${ }^{13}$ Likewise, in our study, predictive postoperative FEV1 was significantly lower in our patients with ARDS than in those without ARDS, but was not an independent predictor of ARDS in multivariate analysis.

Comorbidities are known to be associated with a higher risk of postoperative respiratory complications. ${ }^{18,25}$ In our reintubated patients, postoperative pneumonia was the most frequent complication leading to reintubation; of 


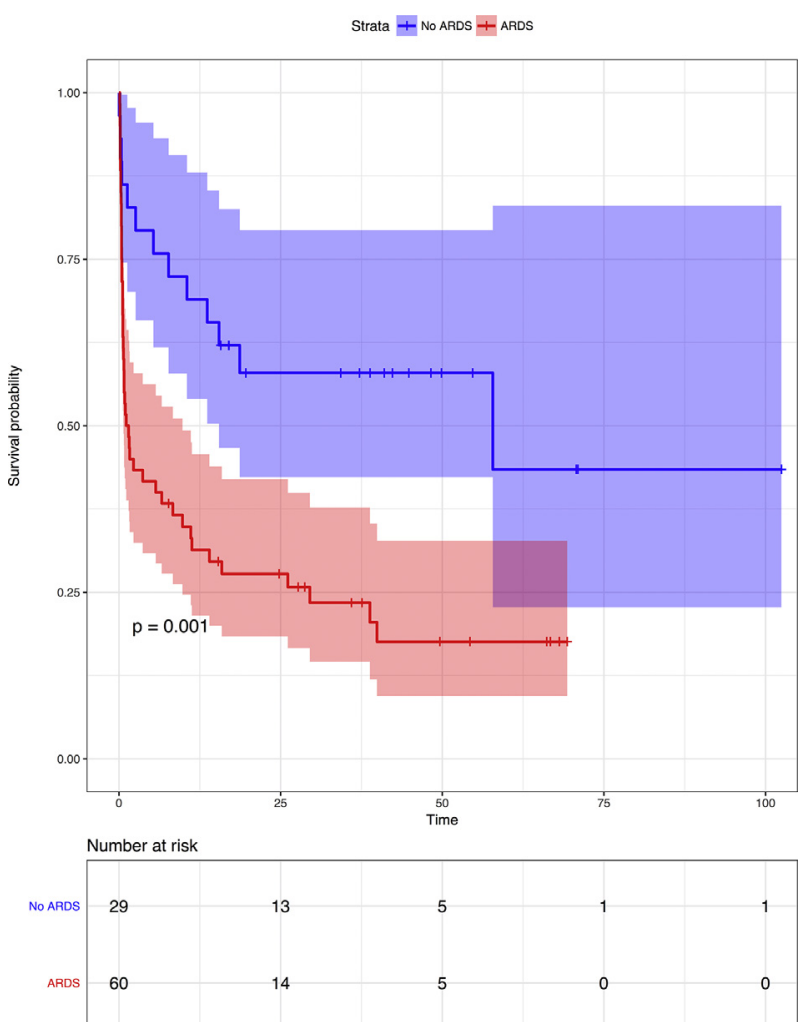

FIGURE 1. Kaplan-Meier estimates of OS of patients with and without ARDS postpneumonectomy. Median duration of survival: ARDS, 1.3 months; $95 \%$ CI, 0.7-9.8. Non-ARDS, 57.8 months; $95 \%$ CI, 15.5 to not available. ARDS, Acute respiratory distress syndrome.

note, the occurrence of postoperative pneumonia was associated with comorbidities, underlining that comorbidities may predispose to pneumonia, which in turn may evolve toward respiratory failure and ARDS. In our patients, postoperative pneumonia was present in $77 \%$ of patients developing ARDS. Of note, comorbidities are also associated with a higher risk of postoperative bleeding, hemorrhagic shock, and need for transfusion, all of these being well-known risk factors for ARDS. ${ }^{2}$

Previous studies identified intraoperative IMV settings and fluid management as modifiable factors associated with the occurrence of postpneumonectomy ARDS. ${ }^{14,26}$ Some studies have also suggested that IMV with higher VTs above the ideal VT of $6 \mathrm{~mL} / \mathrm{kg}$ and high plateau pressure $\left(>25 \mathrm{~cm} \mathrm{H}_{2} \mathrm{O}\right)$ may increase the risk of postoperative lung injury, although these threshold values are debated. ${ }^{14,26}$ Low VT and plateau pressure, applying PEEP during intraoperative IMV, may protect from the subsequent development of ARDS. ${ }^{14}$ In our patients, intraoperative values of VT or plateau pressure were not associated with postpneumonectomy ARDS, which probably relates to the strict implementation of the earlier recommended settings for intraoperative IMV in our institution during the whole study period.

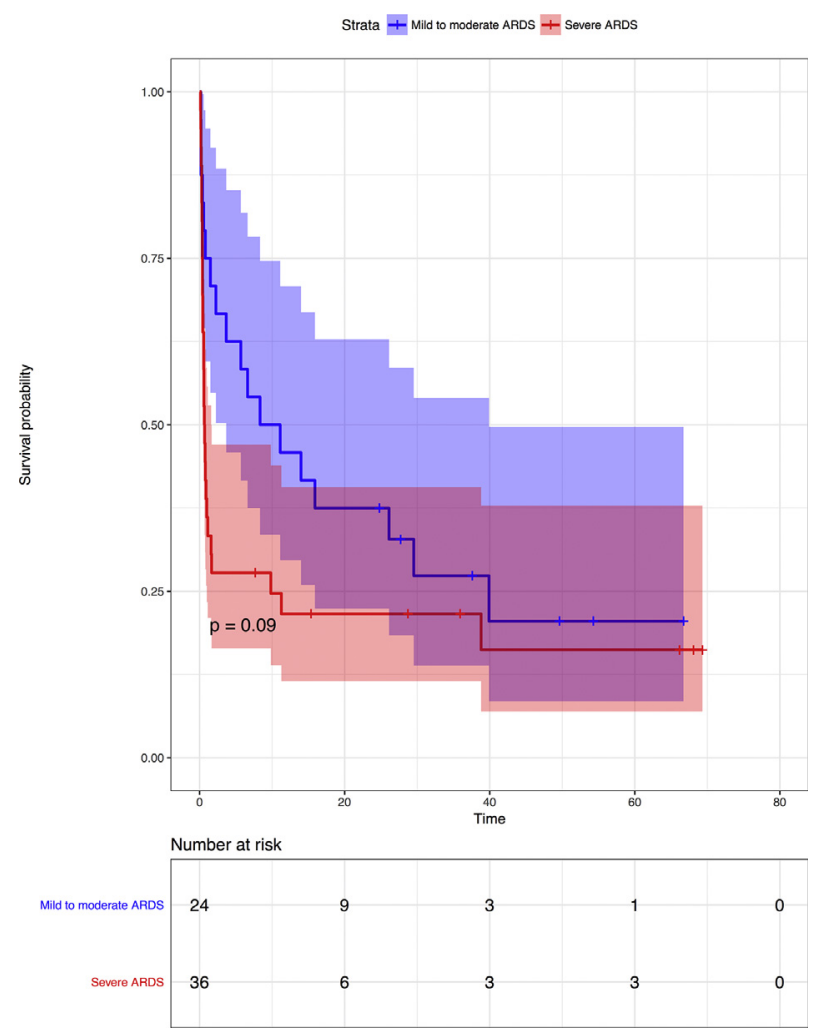

FIGURE 2. Kaplan-Meier estimates of OS of mild and moderate versus severe postpneumonectomy ARDS. Median duration of survival: mild to moderate ARDS, 9.7 months; 95\% CI, 3.7-39.9; severe ARDS, 0.7 months; 95\% CI, 0.4-1.6. ARDS, Acute respiratory distress syndrome.

In our patients with ARDS, factors significantly associated with early mortality were age, right-side pneumonectomy, and severe ARDS. Age is an independent prognostic factor of mortality, as in many other postpneumonectomy survival studies. ${ }^{27}$ Severe ARDS was an independent risk factor of mortality. Indeed, our patients with severe ARDS ( $60 \%$ of all ARDS) had a 2 -fold increased risk of operative mortality than patients with mild or moderate ARDS. These results underline the relevance of the ARDS Berlin definition and of $\mathrm{PaO}_{2} / \mathrm{FIO}_{2}$ ratio to evaluate ARDS severity and prognosis after pneumonectomy.

The mortality rate of postpneumonectomy ARDS was $56.6 \%$ in our study. This figure is higher than in a recent, multicentric study on ARDS (secondary to various causes), in which the mortality rate was $34.8 \%{ }^{28}$ Nevertheless, the mortality rate found in our cohort is in the range of the few available data concerning the specific situation of postpneumonectomy ARDS. Dulu and colleagues' cohort study ${ }^{3}$ (from 2002 to 2004) showed a 50\% mortality rate, whereas Tang and colleagues ${ }^{4}$ reported an $80 \%$ mortality rate from 1991 to 1997 , and a $50 \%$ mortality rate from 2000 to 2005 . In our experience, a similar time-trend of mortality was observed (Figure E1). "High-volume" centers ${ }^{29}$ (as ours) and the presence of multidisciplinary team including 


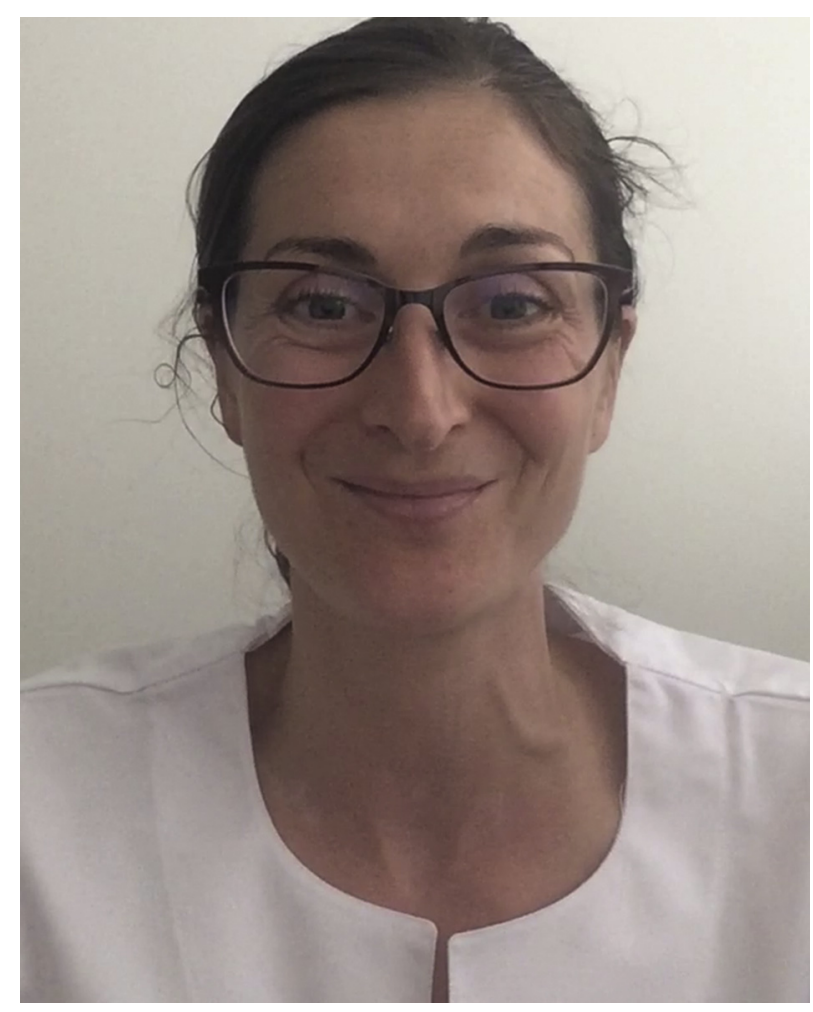

VIDEO 1. Early ARDS after pneumonectomy: Why you should read this article. Video available at: https://www.jtcvs.org/article/S0022-5223(18) 31755-0/fulltext.

surgeons, pulmonologists, intensivists, physiotherapists, nutritionists, and nurses in dedicated thoracic ICUs probably would provide satisfactory results in this extreme severe condition. Furthermore, as shown in the Supplementary Material, mortality rates after postpneumonectomy ARDS seem to decrease with time, although we did not perform a time-sensitive analysis.

In regard to patients with ARDS, this study underlines that in real life, strict application of guidelines is a difficult task and the ventilatory strategy applied in these patients could be improved. During IMV, $25 \%$ of our patients with ARDS were managed with an actual VT greater than $6 \mathrm{~mL} / \mathrm{kg}$ predicted body weight or with a mean plateau pressure higher than $25 \mathrm{~cm} \mathrm{H}_{2} \mathrm{O}$; PEEP values were rather low $\left(6.5 \pm 2.2 \mathrm{~cm} \mathrm{H}_{2} \mathrm{O}\right)$ compared with the values usually applied in patients with ARDS. This findings underline that applying a lung protective strategy with a low plateau pressure and high PEEP in such patients is difficult. The best settings to provide a protective MV after pneumonectomy are not known. A VT of $6 \mathrm{~mL} / \mathrm{kg}$ predicted body weight is probably already too high to keep a plateau pressure below $30 \mathrm{~cm} \mathrm{H}_{2} \mathrm{O}$ when applying high PEEP levels. Setting the IMV according to the driving pressure may be more efficient to increase alveolar recruitment and avoid alveolar lesions. ${ }^{30}$ Further decreasing VT values to 5 or $4 \mathrm{~mL} / \mathrm{kg}$ predicted body weight may be envisaged but often results in severe hypercapnia that is difficult to manage without an extracorporeal $\mathrm{CO}_{2}$ removal system. ${ }^{31-33}$ Only a few cases of extracorporeal membrane oxygenation use to support severe ARDS after pneumonectomy have been reported in the literature, ${ }^{34}$ and further evaluation of this invasive salvage therapy is needed.

We observed a $17.6 \% 5$-year survival in patients with ARDS, confirming the poor outcomes of these patients. A recently published study reported a 5-year survival after pneumonectomy for lung cancer of approximately $35 \%$, and ARDS per se might negatively affect long-term outcome by further lowering postoperative lung function or preventing patients from receiving optimal adjuvant treatments.

\section{Study Strengths and Limitations}

We were able to collect many baseline characteristics, lung function and pathologic variables, and intraoperative and postoperative data. To our knowledge, this is the first study considering all these parameters when analyzing outcomes of patients with postpneumonectomy ARDS. The main limitation is the retrospective character of the study and the presence of some missing data. Thus, causes of late deaths were not available, and we cannot state if they were disease related or not. Likewise, time relationship (and, as a consequence, possible causal relationship) between occurrence of BF and ARDS is difficult to ascertain precisely in this retrospective study. Furthermore, we did not have reliable information about the occurrence of postoperative atrial fibrillation. In addition, a possible hydrostatic origin of pulmonary edema was systematically ruled out by clinical and echocardiographic assessment, and our policy of atrial fibrillation management is based on correction of possibly underlying causes (anemia, hypovolemia, hypokalemia), administration of magnesium sulfate, and, in cases not responding, administration of calcium-channels blockers, avoiding amiodarone. With respect to treatment of pulmonary artery hypertension associated with ARDS, we did not use sildenafil or milrinone, but preferred inhaled nitric oxide, which was administered to 19 patients. Phosphodiesterase inhibitors might have a positive impact on postpneumonectomy ARDS, but this requires specifically designed studies. Finally, the results of this single-center study may reflect only local care and policies and may not apply to other centers.

\section{CONCLUSIONS}

Our study underlines that the management of ARDS in patients undergoing pneumonectomy remains challenging (Video 1). The low survival for patients with severe ARDS suggests the need to develop and test new management strategies.

\section{Conflict of Interest Statement}

Authors have nothing to disclose with regard to commercial support. 


\section{References}

1. Schussler O, Alifano M, Dermine H, Strano S, Casetta A, Sepulveda S, et al. Postoperative pneumonia after major lung resection. Am J Respir Crit Care Med. 2006;173:1161-9.

2. Algar FJ, Alvarez A, Salvatierra A, Baamonde C, Aranda JL, López-Pujol FJ Predicting pulmonary complications after pneumonectomy for lung cancer. Eur J Cardiothorac Surg. 2003;23:201-8.

3. Dulu A, Pastores SM, Park B, Riedel E, Rusch V, Halpern NA. Prevalence and mortality of acute lung injury and ARDS after lung resection. Chest. 2006; 130:73-8.

4. Tang SSK, Redmond K, Griffiths M, Ladas G, Goldstraw P, Dusmet M. The mortality from acute respiratory distress syndrome after pulmonary resection is reducing: a 10-year single institutional experience. Eur J Cardiothorac Surg. 2008;34:898-902.

5. Hamaji M, Keegan MT, Cassivi SD, Shen KR, Wigle DA, Allen MS, et al. Outcomes in patients requiring mechanical ventilation following pneumonectomy. Eur J Cardiothorac Surg. 2014;46:e14-9.

6. Kutlu CA, Williams EA, Evans TW, Pastorino U, Goldstraw P. Acute lung injury and acute respiratory distress syndrome after pulmonary resection. Ann Thorac Surg. 2000;69:376-80.

7. Ruffini E, Parola A, Papalia E, Filosso PL, Mancuso M, Oliaro A, et al. Frequency and mortality of acute lung injury and acute respiratory distress syndrome after pulmonary resection for bronchogenic carcinoma. Eur J Cardiothorac Surg. 2001;20:30-7.

8. Janet-Vendroux A, Loi M, Bobbio A, Lococo F, Lupo A, Ledinot P, et al. Which is the role of pneumonectomy in the era of parenchymal-sparing procedures? Early/long-term survival and functional results of a single-center experience. Lung. 2015;193:965-73.

9. Alam N, Park BJ, Wilton A, Seshan VE, Bains MS, Downey RJ, et al. Incidence and risk factors for lung injury after lung cancer resection. Ann Thorac Surg. 2007;84:1085-91.

10. Jeon K, Yoon JW, Suh GY, Kim J, Kim K, Yang M, et al. Risk factors for postpneumonectomy acute lung injury/acute respiratory distress syndrome in primary lung cancer patients. Anaesth Intensive Care. 2009;37:14-9.

11. Kim JB, Lee SW, Park S-I, Kim YH, Kim DK. Risk factor analysis for postoperative acute respiratory distress syndrome and early mortality after pneumonectomy: the predictive value of preoperative lung perfusion distribution. $J$ Thorac Cardiovasc Surg. 2010;140:26-31.

12. Licker M, de Perrot M, Spiliopoulos A, Robert J, Diaper J, Chevalley C, et al. Risk factors for acute lung injury after thoracic surgery for lung cancer. Anesth Analg. 2003;97:1558-65.

13. Parquin F, Marchal M, Mehiri S, Hervé P, Lescot B. Post-pneumonectomy pulmonary edema: analysis and risk factors. Eur J Cardiothorac Surg. 1996;10: 929-33.

14. Licker M, Diaper J, Villiger Y, Spiliopoulos A, Licker V, Robert J, et al. Impact of intraoperative lung-protective interventions in patients undergoing lung cancer surgery. Crit Care Lond Engl. 2009;13:R41.

15. The ARDS Definition Task Force*. Acute respiratory distress syndrome: the Berlin definition. JAMA. 2012;307:2526-33.

16. Rezoagli E, Fumagalli R, Bellani G. Definition and epidemiology of acute respiratory distress syndrome. Ann Transl Med. 2017;5:282.

17. Darling GE, Abdurahman A, Yi Q-L, Johnston M, Waddell TK, Pierre A, et al. Risk of a right pneumonectomy: role of bronchopleural fistula. Ann Thorac Surg. 2005;79:433-7.

18. Thomas PA, Berbis J, Baste J-M, Le Pimpec-Barthes F, Tronc F, Falcoz P-E, et al. Pneumonectomy for lung cancer: contemporary national early morbidity and mortality outcomes. J Thorac Cardiovasc Surg. 2015;149:73-82.

19. Foroulis CN, Kotoulas CS, Kakouros S, Evangelatos G, Chassapis C, Konstantinou M, et al. Study on the late effect of pneumonectomy on right heart pressures using Doppler echocardiography. Eur J Cardiothorac Surg. 2004;26: 508-14.

20. van der Werff YD, van der Houwen HK, Heijmans PJ, Duurkens VA, Leusink HA, van Heesewijk HP, et al. Postpneumonectomy pulmonary edema. A retrospective analysis of incidence and possible risk factors. Chest. 1997; 111:1278-84.

21. Bigatello LM, Allain R, Gaissert HA. Acute lung injury after pulmonary resection. Minerva Anestesiol. 2004;70:159-66.

22. Lewis JW, Bastanfar M, Gabriel F, Mascha E. Right heart function and prediction of respiratory morbidity in patients undergoing pneumonectomy with moderately severe cardiopulmonary dysfunction. J Thorac Cardiovasc Surg. 1994;108: $169-75$.

23. Fee HJ, Holmes EC, Gewirtz HS, Ramming KP, Alexander JM. Role of pulmonary vascular resistance measurements in preoperative evaluation of candidates for pulmonary resection. J Thorac Cardiovasc Surg. 1978;75:519-24.

24. Rams JJ, Harrison RW, Fry WA, Moulder PV, Adams WE. Operative pulmonary artery pressure measurements as a guide to postoperative management and prognosis following pneumonectomy. Dis Chest. 1962;41:85-90.

25. Arozullah AM, Khuri SF, Henderson WG, Daley J. Participants in the national veterans affairs surgical quality improvement program. Development and validation of a multifactorial risk index for predicting postoperative pneumonia after major noncardiac surgery. Ann Intern Med. 2001;135:847-57.

26. Evans RG, Naidu B. Does a conservative fluid management strategy in the perioperative management of lung resection patients reduce the risk of acute lung injury? Interact Cardiovasc Thorac Surg. 2012;15:498-504.

27. Pricopi C, Mordant P, Rivera C, Arame A, Foucault C, Dujon A, et al. Postoperative morbidity and mortality after pneumonectomy: a 30-year experience of 2064 consecutive patients. Interact Cardiovasc Thorac Surg. 2015;20:316-21.

28. Bellani G, Laffey JG, Pham T, Fan E, Brochard L, Esteban A, et al. Epidemiology, patterns of care, and mortality for patients with acute respiratory distress syndrome in intensive care units in 50 countries. JAMA. 2016;315:788-800.

29. Strand T-E, Rostad H, Damhuis RAM, Norstein J. Risk factors for 30-day mortality after resection of lung cancer and prediction of their magnitude. Thorax. 2007;62:991-7.

30. Guérin C, Papazian L, Reignier J, Ayzac L, Loundou A, Forel JM, Investigators of the Acurasys and Proseva trials. Effect of driving pressure on mortality in ARDS patients during lung protective mechanical ventilation in two randomized controlled trials. Crit Care. 2016;20:384.

31. Terragni PP, Del Sorbo L, Mascia L, Urbino R, Martin EL, Birocco A, et al. Tidal volume lower than $6 \mathrm{ml} / \mathrm{kg}$ enhances lung protection: role of extracorporeal carbon dioxide removal. Anesthesiology. 2009;111:826-35.

32. Bein T, Weber-Carstens S, Goldmann A, Müller T, Staudinger T, Brederlau J, et al. Lower tidal volume strategy $(\approx 3 \mathrm{ml} / \mathrm{kg}$ ) combined with extracorporeal $\mathrm{CO} 2$ removal versus "conventional" protective ventilation $(6 \mathrm{ml} / \mathrm{kg})$ in severe ARDS: the prospective randomized Xtravent-study. Intensive Care Med. 2013; 39:847-56.

33. Fanelli V, Ranieri MV, Mancebo J, Moerer O, Quintel M, Morley S, et al. Feasibility and safety of low-flow extracorporeal carbon dioxide removal to facilitate ultra-protective ventilation in patients with moderate acute respiratory distress syndrome. Crit Care. 2016;20:36.

34. Marek S, Martin S, Ondrej Z, Josef C, Cestmir N, Vladimir L. Extracorporeal membrane oxygenation in the management of post-pneumonectomy air leak and adult respiratory distress syndrome of the non-operated lung. Perfusion. 2017;32:416-8

Key Words: acute respiratory distress syndrome, acute respiratory failure, lung cancer, outcome, pneumonectomy, protective ventilation 


\section{SUPPLEMENTARY METHODS Data Collection}

The following baseline patient characteristics were recorded: age, sex, smoking history including active smoking or past smoking, obesity (defined as a body mass index $>30 \mathrm{~kg} / \mathrm{m}^{2}$ ), chronic alcoholic abuse (defined by a consumption $>30 \mathrm{~g}$ per day for men and $>20 \mathrm{~g}$ per day for women), diabetes mellitus, systemic arterial hypertension, chronic cardiac disease (defined as chronic atrial fibrillation or chronic coronary arterial disease), CCI, and Performance Status greater than 1, according to Eastern Cooperative Oncology Group stage. ${ }^{\mathrm{E} 1}$

The following respiratory function characteristics were recorded: presence of COPD (diagnosis based on FEV1/ forced vital capacity ratio $<70 \%$ ), percent lung diffusing capacity for carbon monoxide/alveolar volume defined as lung diffusing capacity for carbon monoxide adjusted for alveolar volume, predictive postoperative FEV1 (calculated on the basis of preoperative FEV1 and the results of lung perfusion scan), ${ }^{\mathrm{E} 2}$ and ratio FEV1/forced vital capacity.

The following tumor-related data were recorded: previous lung cancer, previous nonlung cancer, side of lung cancer, pathology: squamous cell carcinoma, adenocarcinoma, other histologic types of lung cancer, mesothelioma, metastasis, other malignancies, benign disease; neoadjuvant chemotherapy or radiotherapy.

The types of resection were recorded, including simple pneumonectomy or extended pneumonectomy (resection extended to neighboring organs, ie, pericardium), extrapleural pneumonectomy, completion pneumonectomy, carinal resection, and the American Society of Anesthesiologists physical status.

The postoperative TNM stage was also recorded.

The following intraoperative data were recorded: American Society of Anesthesiologists score above II, duration of general anesthesia, Cormack III or IV status, epidural analgesia, intraoperative fluid infusion volume, transfusion or not, VT before and after pulmonary exclusion compared with the VT of $6 \mathrm{~mL} / \mathrm{kg}$ of predicted body weight, and plateau pressure.

We recorded patients' characteristics at ICU admission: Simplified Acute Physiologic Score 2 score, Sequential Organ Failure Assessment scores at day 1 and day 3 of admission, postoperative complications occurring before reintubation leading to ventilation: postoperative pneumonia, atelectasis, COPD decompensation, cardiogenic pulmonary edema, pulmonary embolism, hemorrhagic shock, and other postoperative complications: sepsis, acute kidney injury, acute coronary syndrome. We also recorded the need for NIV before orotracheal intubation or not and the time between admission and reintubation.

The following data concerning ARF support and outcome were recorded: Sequential Organ Failure
Assessment score at intubation, ARF severity at intubation: $\mathrm{pH}$, partial pressure of carbon dioxide in arterial blood, $\mathrm{PaO}_{2} / \mathrm{FIO}_{2}$. At 24 hours after intubation, under sedation, and after hemodynamic optimization, patients were classified as non-ARDS and ARDS (separated as mild, moderate, and severe ARDS according to the Berlin definition). ${ }^{\mathrm{E} 3}$ The following data concerning MV were recorded: mean VT and its ratio to the $6 \mathrm{~mL} / \mathrm{kg}$ VT of predicted body weight (ideal VT), PEEP, plateau pressure. Use of neuromuscular blockade, prone or lateral positioning, inhaled nitric oxide, high dose of corticosteroids, extracorporeal membrane oxygenation, vasopressors, RRT, and tracheotomy were also recorded. MV complications, such as ventilatorassociated pneumonia, BF, and empyema, were recorded. We calculated duration of MV, ICU and hospital length of stay, and 30-day and operative mortality.

\section{Preoperative Evaluation}

For every patient, preoperative evaluation consisted of symptoms, physical examination, basic blood tests, pulmonary function tests, and lung perfusion scan. TNM stage was evaluated with fiber optic bronchoscopy, contrast-enhanced chest and upper abdominal computed tomography scan, brain computed tomography scan or brain magnetic resonance imaging, and 18-FDG positron emission tomography scan. Cardiac assessment was evaluated by cardiovascular history, electrocardiogram, and transthoracic echocardiograph. Coronary angiography or a cardiac stress test could be performed to complete the evaluation. If the pulmonary function test results were abnormal, an exercise testing peak $\mathrm{VO}_{2}\left(\mathrm{VO}_{2}\right.$ max or stair climbing test) was assessed. Patients were considered suitable for surgery if predicted postoperative FEV1 was above $30 \%$ of theory, there was no hypercapnia $(>46 \mathrm{~mm} \mathrm{Hg}$ ), and there was no pulmonary hypertension. ${ }^{\mathrm{E} 2}$ Patients could benefit from pulmonary rehabilitation to improve their pulmonary function before surgery. Preoperative chemotherapy or radiotherapy could be administered before surgery to downstage the tumor.

\section{Intraoperative Care}

All patients were intubated with a double-lumen tube. Perioperative antimicrobial prophylaxis was administered according to the local guidelines. When the pleural space was opened, single-lung ventilation was used. The ventilation administered was a positive pressure mode. Plateau pressure was assimilated to peak pressure. Recruitment maneuvers could be performed. Fluid infusions were limited, and vasopressors could be administered. Surgical techniques were those of standard pulmonary resections. A multimodal analgesia was administered, including a thoracic paravertebral block at the end of surgery. Epidural analgesia was not systematic and was administered if a thoracic parietal resection was considered or if predicted postoperative FEV1 was just above $30 \%$ to prevent 
pulmonary postoperative complications with a better analgesia. Most of the patients were extubated in the recovery room. Those who could not be were extubated in the ICU.

\section{Postoperative Care}

Postoperative management consisted of early mobilization, chest physiotherapy, aerosolized bronchodilators, and controlled multimodal analgesia including epidural or paravertebral block. If needed, supplemental oxygen was given through nasal cannula to achieve oxygen saturation above $92 \%$. Oral realimentation was started on postoperative day 1 . No suction was applied on postpneumonectomy chest tube. The chest tube was withdrawn on day 2 .

Simplified Acute Physiologic Score 2 and Sequential Organ Failure Assessment score ${ }^{\mathrm{E} 4}$ at days 1 and 3 were recorded. When the patients were receiving nasal oxygen therapy, the correspondence table to $\mathrm{FIO}_{2}$ was as follows:

\begin{tabular}{ll}
\hline \multicolumn{1}{c}{$\mathbf{O 2}=\mathbf{L} / \mathbf{m i n}$} & $\mathbf{F i O}_{\mathbf{2}} \%$ \\
\hline 0 & 21 \\
0.5 & 22 \\
1 & 24 \\
2 & 28 \\
\hline 3 & 32 \\
4 & 36 \\
5 & 40 \\
6 & 44 \\
9 & 60 \\
12 (high concentration oxygen mask) & 70 \\
15 & 80 \\
20 & 100 \\
30 & 100 \\
\hline
\end{tabular}

\section{Definitions}

- ARDS diagnosis and severity classification follow the Berlin ARDS definition and are defined by the absence of suspected hydrostatic or cardiogenic pulmonary edema and $\mathrm{PaO}_{2} / \mathrm{FIO}_{2} 300 \mathrm{~mm} \mathrm{Hg}$ or less, divided into 3 groups: mild (200 mm Hg $<\mathrm{PaO}_{2} / \mathrm{FIO}_{2} \leq 300 \mathrm{~mm} \mathrm{Hg}$ ), moderate $\left(100<\mathrm{PaO}_{2} / \mathrm{FIO}_{2} \leq 200 \mathrm{~mm} \mathrm{Hg}\right)$, and severe ARDS $\left(\mathrm{PaO}_{2} / \mathrm{FIO}_{2} \leq 100 \mathrm{~mm} \mathrm{Hg}\right)$, assessed with a PEEP level $\geq 5 \mathrm{~cm} \mathrm{H}_{2} \mathrm{O}$.

- ARF was defined by the presence and persistence of at least 2 of the following: respiratory acidosis (arterial $\mathrm{pH}<7.35$ together with partial pressure of carbon dioxide in arterial blood $>50 \mathrm{~mm} \mathrm{Hg}$ ); arterial oxygen saturation by pulse oximetry of less than $90 \%$ or $\mathrm{PaO}_{2}$ lower than $60 \mathrm{~mm} \mathrm{Hg}$ at $\mathrm{FIO}_{2}$ of 0.5 or nasal oxygen therapy at $8 \mathrm{~L} / \mathrm{min}$; respiratory rate greater than 30 breaths per minute; clinical signs of ARF (ie, cyanosis, sweats, involvement of accessory respiratory muscles, paradoxical abdominal motion, and consciousness impairment).

- Atelectasis was defined as a reduction in lung volume, loss of aeration, and displacement in interlobar fissures on chest radiograph, with a rapid improvement after fiberoptic bronchoscopy, chest physiotherapy, or MV.

- Sepsis was defined by a systemic inflammatory response of the host to an infectious aggression.

- Acute kidney injury was defined by the "risk stage" of the RIFLE classification: increase of creatinine level by 1.5 its concentration before surgery.

- Acute myocardial infarction was defined by an ischemic cardiac dysfunction due to coronary stenosis or emboli.

- COPD decompensation was defined as a life-threating exacerbation of COPD (exacerbation defined by the presence of at least 2 of the following signs and symptoms: change in baseline dyspnea, cough, or sputum quantity or purulence).

- Cardiac pulmonary edema was defined by an increased capillary hydrostatic pressure secondary to elevated pulmonary venous pressure, resulting in cardiac dysfunction.

- Hemorrhagic shock was defined by an excess of bleeding associated with arterial hypotension not responding to fluid infusion and resulting in the use of vasopressors.

- Ventilator-associated pneumonia was defined according to microbiological culture results from distal bronchial sampling with identification of a pathogen (quantitative bronchoalveolar lavage with a cutoff value $>10^{4} \mathrm{UFC} /$ $\mathrm{mL}$ or quantitative bronchial aspirate with a cutoff value $>10^{6} \mathrm{UFC} / \mathrm{mL}$ ) and administration of related antibiotic treatment.

- BF was confirmed by direct fiber optic bronchoscopy visualization in all cases. Empyema was defined as the presence of purulent fluid in the pleural drainage or as the isolation of pathogens from the pleural cavity.

\section{SUPPLEMENTAL DISCUSSION}

Of 89 patients requiring reintubation, $59.6 \%$ were initially managed with NIV before reintubation, and delayed reintubation seemed to be associated with a higher rate of ARDS. During NIV, which is a pressure-assist spontaneous ventilation mode, VT is not controlled and hypoxemic patients may generate high transpulmonary pressure swings; thus, NIV may favor or worsen lung injury by means of volutrauma and alveolar stretching. ${ }^{\text {E5 }}$ Our findings suggest that in patients with hypoxemic ARF after pneumonectomy, the lack of early improvement under NIV should lead to prompt intubation. 


\section{E-References}

E1. Oken M, Creech RH, Tormey DC, Horton J, Davis TE, McFadden ET. Toxicity and response criteria of the Eastern Cooperative Oncology Group. Am J Clin Oncol. 1982;5:649-55

E2. Cancers bronchopulmonaires et pleuraux - Recommandations et outils d'aide à la pratique | Institut National Du Cancer. Available at: http://www.e-cancer.fr/ Professionnels-de-sante/Recommandations-et-outils-d-aide-a-la-pratique/Cancersbronchopulmonaires-et-pleuraux. Accessed March 15, 2016.

E3. The ARDS Definition Task Force*. Acute respiratory distress syndrome: the Berlin definition. JAMA. 2012;307:2526-33.

E4. Vincent JL, Moreno R, Takala J, Willatts S, De Mendonça A, Bruining H, et al The SOFA (Sepsis-related Organ Failure Assessment) score to describe organ dysfunction/failure. On behalf of the working group on sepsis-related problems of the European Society of Intensive Care Medicine. Intensive Care Med. 1996; 22:707-10.

E5. Carteaux G, Millán-Guilarte T, De Prost N, Razazi K, Abid S, Thille AW, et al. Failure of noninvasive ventilation for de novo acute hypoxemic respiratory failure: role of tidal volume. Crit Care Med. 2016;44:282-90.

Relative risk of 30-day mortality

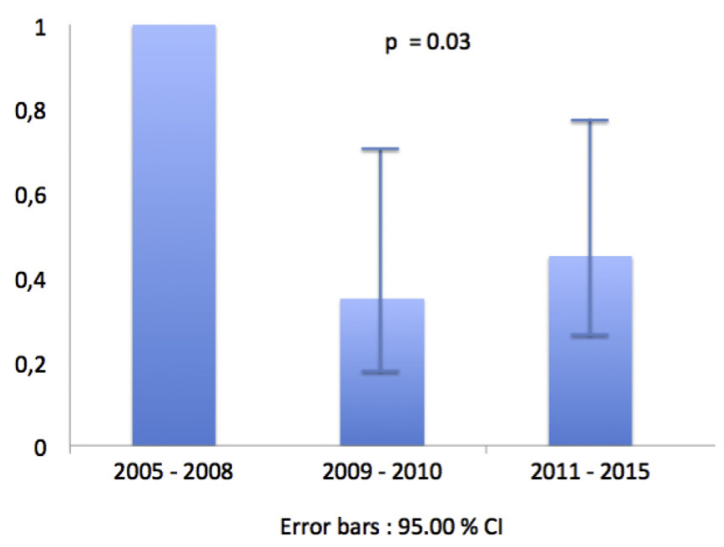

FIGURE E1. Relative risk of 30-day mortality according to period of admission to ICU. Reference period 2005-2008: $n=26$ patients, 20092010: $\mathrm{n}=26$ patients, 2011-2015: $\mathrm{n}=37$ patients, 2009-2010: OR, 0.45; 95\% CI, 0.26-0.79; 2011-2015: OR, 0.35; 95\% CI, 0.18-0.69. CI, Confidence interval. 
TABLE E1. Intraoperative management, comparing patients with and without acute respiratory distress syndrome

\begin{tabular}{|c|c|c|c|c|}
\hline Parameters & $\begin{array}{l}\text { All intubated patients } \\
\qquad \mathbf{n}=\mathbf{8 9}\end{array}$ & $\begin{aligned} & \text { ARDS } \\
\mathbf{n}= & 60(67.4 \%)\end{aligned}$ & $\begin{array}{c}\text { Non-ARDS } \\
\mathbf{n}=\mathbf{2 9}(\mathbf{3 2 . 6} \%)\end{array}$ & $P$ value \\
\hline ASA III/IV, n (\%) & $57(64)$ & $39(65)$ & $18(62.1)$ & .79 \\
\hline Duration of surgery $(\mathrm{h})$, median [IQR] & $4.5[4-6]$ & $4.5[4-6]$ & $4.5[4-5.5]$ & .59 \\
\hline Cormack III/IV, n (\%) & $9(10.1)$ & $3(5)$ & $6(20.7)$ & $.054 *$ \\
\hline Fluid infusion (L), median [IQR] & $2[1.5-3]$ & $2[1.5-3]$ & $2.5[2-3]$ & .09 \\
\hline Transfusion, $\mathrm{n}(\%)$ & $17(19.1)$ & $11(18.3)$ & $6(20.7)$ & .79 \\
\hline VT before exclusion/iVT, median [IQR] & $1.16[1.05-1.27]$ & 1.15 [1.07-1.25] & $1.17[0.98-1.35]$ & .87 \\
\hline VT after exclusion/iVT, median [IQR] & $1.03[0.92-1.16]$ & $1.02[0.93-1.15]$ & $1.03[0.91-1.20]$ & .78 \\
\hline Plateau pressure, median [IQR] & 25 [22-28] & $25[20-28]$ & $25[23-28]$ & .51 \\
\hline Epidural analgesia, n (\%) & $13(14.6)$ & $10(16.7)$ & $3(10.3)$ & .53 \\
\hline
\end{tabular}

Continuous variables are reported as median [IQR Q1Q3]. Categoric variables are reported as number (percentages). ARDS, Acute respiratory distress syndrome; ASA, American Society of Anesthesiologists; IQR, interquartile range; $V T$, tidal volume; $i V T$, ideal tidal volume according to $6 \mathrm{~mL} / \mathrm{kg}$ of predicted body weight. *Fisher exact test.

TABLE E2. Postoperative intensive care unit complications occurring before acute respiratory distress syndrome onset, comparing patients with and without acute respiratory distress syndrome

\begin{tabular}{|c|c|c|c|c|}
\hline & $\begin{array}{c}\text { All intubated } \\
\text { patients } n=89\end{array}$ & $\begin{aligned} & \text { ARDS } \\
\mathbf{n}= & 60(67.4 \%)\end{aligned}$ & $\begin{array}{c}\text { Non-ARDS } \\
\mathbf{n}=\mathbf{2 9}(32.6 \%)\end{array}$ & $P$ value \\
\hline SAPS2, median [IQR] & $27[19-36]$ & $26[16-35.5]$ & 30 [21-39] & .24 \\
\hline SOFA day 1 , median [IQR] & $2[1-7]$ & $2[1-5]$ & $4[2-8]$ & .07 \\
\hline SOFA day 3, median [IQR] & $3[1-8]$ & $4[2-10]$ & $1[0-4]$ & .002 \\
\hline \multicolumn{5}{|l|}{ Indications for ventilation } \\
\hline Pneumonia, n (\%) & $57(64)$ & $46(76.7)$ & $11(38)$ & .0004 \\
\hline Atelectasis, n (\%) & $13(14.6)$ & $9(15)$ & $4(13.8)$ & $1 *$ \\
\hline COPD decompensation, $\mathrm{n}(\%)$ & $50(56.2)$ & $36(60)$ & $14(48.3)$ & .30 \\
\hline Cardiac pulmonary edema, $\mathrm{n}(\%)$ & $9(10)$ & $6(10)$ & $3(10.3)$ & $1^{*}$ \\
\hline Pulmonary embolism, n (\%) & $2(2.2)$ & $0(0)$ & $2(7)$ & $.10^{*}$ \\
\hline Hemorrhagic shock, n (\%) & $16(18)$ & 7 (11.7) & $9(31)$ & .03 \\
\hline \multicolumn{5}{|l|}{ Other postoperative complications } \\
\hline Sepsis, n (\%) & $63(70.8)$ & $52(86.7)$ & $11(38)$ & $<.0001$ \\
\hline Acute kidney injury, n (\%) & $33(37)$ & $24(40)$ & $9(31)$ & .41 \\
\hline Acute coronary syndrome, $\mathrm{n}(\%)$ & $12(13.5)$ & $7(11.7)$ & $5(17.2)$ & $.52 *$ \\
\hline NIV for ARF before intubation, $\mathrm{n}(\%)$ & $53(59.6)$ & $44(73.3)$ & $9(31)$ & .0001 \\
\hline Time between admission and intubation, (d), median [IQR] & $2[0-4]$ & $3[1-4]$ & $0[0-3]$ & .007 \\
\hline
\end{tabular}

Continuous variables are reported as median [IQR (Q1Q3)]. Categoric variables are reported as number (percentages). ARDS, Acute respiratory distress syndrome; SAPS, Simplified Acute Physiologic Score; IQR, interquartile range; SOFA, Sequential Organ Failure Assessment; COPD, chronic obstructive pulmonary disease; NIV, noninvasive ventilation; $A R F$, acute respiratory failure. *Fisher exact test. 
TABLE E3. Clinical characteristics, management, and outcome of intubated patients, comparing patients with and without acute respiratory distress syndrome

\begin{tabular}{|c|c|c|c|c|}
\hline & All reintubated patients $n=89$ & ARDS n $=60(67.4 \%)$ & Non-ARDS $n=29(32.6 \%)$ & $P$ value \\
\hline SOFA at intubation, median [IQR] & $8[4.5-11]$ & 9 [6-12] & $6[4-9]$ & .01 \\
\hline SOFA at day 3 of IMV, median [IQR] & $6[2-10]$ & $8[4-11]$ & $2[0-4]$ & $<.0001$ \\
\hline $\mathrm{pH}$, median [IQR] & $7.30[7.23-7.38]$ & $7.30[7.23-7.38]$ & $7.31[7.21-7.39]$ & .99 \\
\hline $\mathrm{PaO}_{2} / \mathrm{FIO}_{2}$, median $[\mathrm{IQR}]$ & 159 [119-290] & 142 [109-200] & 280 [158-357] & .001 \\
\hline VT/iVT, median [IQR] & $1.03[0.92-1.16]$ & $1.02[0.93-1.15]$ & $1.03[0.91-1.20]$ & .78 \\
\hline PEEP $\left(\mathrm{cm} \mathrm{H}_{2} \mathrm{O}\right)$, median [IQR] & $5[5-6]$ & $5[5-8]$ & $5[5-5]$ & .10 \\
\hline Plateau pressure $\left(\mathrm{cm} \mathrm{H}_{2} \mathrm{O}\right)$, median [IQR] & $24[18-28]$ & 26 [22-29] & 19.5 [17-24] & .008 \\
\hline Tracheotomy, n (\%) & $27(30.3)$ & $24(40)$ & $3(10.3)$ & .004 \\
\hline Vasopressors, $\mathrm{n}(\%)$ & $66(74.2)$ & $48(80.0)$ & $18(62.1)$ & .07 \\
\hline RRT, n (\%) & $12(13.5)$ & $9(15.0)$ & $3(10.3)$ & $.74 *$ \\
\hline VAP, n $(\%)$ & $44(49.4)$ & $40(66.7)$ & $4(13.8)$ & $<.0001$ \\
\hline Fistula, n (\%) & $15(16.8)$ & $15(25)$ & $0(0)$ & $.001 *$ \\
\hline Empyema, n (\%) & $17(19.1)$ & $14(23.3)$ & $3(10.3)$ & .14 \\
\hline Duration of MV (d), median [IQR] & $6[2-18]$ & $11[5-26]$ & $2[2-3]$ & $<.0001$ \\
\hline ICU LOS, median [IQR] & 14 [7-28] & $18[10-36]$ & $8[5-15]$ & .0009 \\
\hline Hospital LOS, median [IQR] & $18[12-34]$ & $21[12-40]$ & $16[12-22]$ & .21 \\
\hline Day 30 mortality, n (\%) & 37 (41.6) & $32(53.3)$ & $5(17.2)$ & .001 \\
\hline
\end{tabular}

Continuous variables are reported as median [IQR (Q1Q3)]. Categoric variables are reported as number (percentages). ARDS, Acute respiratory distress syndrome; SOFA, Sequential Organ Failure Assessment; IQR, interquartile range; $I M V$, invasive mechanical ventilation; $\mathrm{PaO}_{2}$, arterial oxygen tension; $\mathrm{FIO}_{2}$, fraction of inspired oxygen; $V T$, tidal volume; $i V T$, ideal tidal volume according to $6 \mathrm{~mL} / \mathrm{kg}$ of predicted body weight; PEEP, positive end-expiratory pressure; RRT, renal replacement therapy; VAP, ventilatorassociated pneumonia; $M V$, mechanical ventilation; $I C U$, intensive care unit; $L O S$, length of stay. *Fisher exact test. 